\title{
The Application of Special Library Services and Techniques to the College Library
}

Advanced library services, common to some special libraries, were applied to certain courses of study in English in five selected colleges. These services included: (1) answering reference questions fully rather than guiding patrons to the answer; (2) the preparation upon request of pertinent bibliographies; (3) notification of faculty members when something appeared in print that they would likely use; and (4) recommendation of books for purchase. Measurement of library use was made among groups receiving these services and among groups not receiving them; no quantifiable differences were observed.

I of services in the college library has found expression in the literature in recent years. Various authors have recommended that special library services and techniques be applied to the college library. In an attempt to provide objective measurement of the effect of their application, a study was made in five college libraries. It was made in cooperation with their departments of English, within the course of one academic year.

The hypothesis of the study was that the provision of "special library" services and techniques by a college library for a current, ongoing course will result in more and better library use by the persons being served than when they are not provided. "College library"

A summary of a doctoral dissertation accepted by the faculty of the Graduate School of Library Service, Rutgers University, in 1964 (215 p.). Copies of the dissertation are available from University Microfilms, Ann Arbor, Michigan.

Miss DeHart is head, Reference Department, Seton Hall University Library. was defined as a main library in a college or university which emphasizes four-year undergraduate instruction and may or may not offer graduate programs leading to a master's or doctor's degree.

The experiment was designed to determine quantitatively the use made of the various services given to the faculty members served and to their students, and the use made of the same materials by control groups who were not provided special services. An attempt was also made to measure the value of the services to the faculty members and their students, in so far as quality can be determined.

The purpose of the first phase of the study was to identify those special library services and techniques worthy of further testing on a broader scale. The following services were provided for eight (seven after one withdrawal) faculty members in one small university in connection with two upper division and two lower division courses, considered by the head of the Department of English to have in their syllabi substantial 
potential for library use: (1) a special reference service giving answers to questions rather than merely indications of where answers might be found; (2) compiling bibliographies upon request, enumerative or annotated; (3) a current awareness service, in which ninety-five current periodicals and Abstracts of English Studies were searched for items pertinent to the courses served, with notification to faculty members of these items through citations or original abstracts and tables of contents when appropriate; (4) a book ordering service, in which book reviews in the ninety-five periodicals were scanned and filled-out order blanks sent for approval to appropriate professors for titles relevant to their courses, as well as filled-out order forms for materials to repair deficiencies in the collection which hindered the provision of services.

These services were not provided in connection with the personal study and research of faculty members unless their study and research happened to coincide in subject matter with the courses served. Neither were the services provided directly to students. The head of the department of English stated that part of the educational goal of the department was to teach students to find materials and information themselves; therefore, they should not have any part of their work done for them.

Quantitative measurement of the use made of the services provided in the first phase of the study indicated that none was worthy of second phase testing in other college libraries. Use was made most consistently and heavily by one professor, bearing out the results of studies cited by Clark, in which individual professors, rather than the items being tested, appeared to be the determining factor in the outcome of the studies. ${ }^{1}$

1 Virginia Clark, "Teaching Students to Use the Library: Whose Responsibility ?" CRL, XXI (September 1960), 372 .
Without a knowledge, however, of the underlying attitudes of the professors toward educational goals and teaching methods, and without a knowledge of whether the services, with their possibly inherent cumulative value, helped to facilitate their teaching and the learning of their students, the meaning of the quantitative statistics could not be fully interpreted. In addition to a knowledge of the attitudes of the professors served, it was necessary to ascertain what other factors, controllable or uncontrollable, were instrumental in helping or hindering the receipt of potential benefit from the services.

Responding to the questionnaires, professors indicated, with respect to the current awareness service in particular, that they would have made more use of the library materials cited if their time schedule, the nature of the articles, and the price of photoduplication had been more favorable. They considered the current awareness service as a potential aid to themselves in providing general background from which to draw in their teaching. Two professors specifically indicated that this service offered cumulative benefits to be reaped at the time of subsequent offerings of their courses.

Since none of the services offered in the first phase of the study proved worthy of further testing in current, ongoing courses, two other services were tested in the second phase of the study, in the original library as well as in four others. Replies to one of the questionnaires sent to professors in the first phase of the study indicated that bibliographical assistance of a librarian in compiling course reading lists would be a desirable service. This service, offered during the second phase of the study, aimed to determine what, if any, of the intellectual parts of the compilation of reading lists could be done or aided by librarians and to measure subsequent use made of the lists prepared by the researcher and/or professors. 
The other service tested was suggested by the head of the department of English of the first college studied: the compilation of a checklist of periodicals of use to students of English language and literature, based on the library's holdings, and giving information not before included in a periodical directory under one cover. It appeared possible that this information would not only aid the student to become familiar with the subject content of periodicals that would be useful to him, but that it would also aid him in using the periodicals more effectively through the inclusion of certain bibliographical information, such as the presence of an index or special bibliography. A number of the periodicals included in the checklists were not indexed in any periodical indexes.

The services described above were provided as follows: reading lists were prepared for one course at each of two of the colleges and for two courses at one college; the checklist of periodicals was distributed to one class of two courses at each of the five colleges, including the first. The checklist was adapted to the holdings of each library at the five institutions and distributed in the name of each library.

Quantitative measurement of the use made of the services provided in the second phase of the study also proved the hypothesis to be false. Comment by professors revealed factors which militated against use of the services: assignments given by professors specifying that the use of library materials was either not required or was forbidden in the preparation of papers; assignment of papers requiring textual analysis of literary works themselves rather than analysis which would include critical material as well; and the use of all-inone textbooks containing bibliography and readings as well as the usual textbook material with the specification that no readings not given in the textbook be assigned.

The services in both phases of the study were provided for courses currently in operation in the department of English; the results of the study may or may not apply to other fields. In respect to the particular services offered, the quantitative and qualitative data, in both phases of the study, proved that this assumption was not justified.

The study did show that while the special library services offered had no impact on the content and methods of teaching of these ongoing courses, they served most of the professors in the first phase and one professor in the second phase as general preparation for the design of the same and other courses in the future. In addition, it was generally agreed that the current awareness service offered in the first phase enriched the background of the professors. There was some indication, therefore, that the usefulness of the services may be broader and of more long-range value than is indicated by their lack of immediate effect on a particular ongoing course. The amount of time and material required to give the services is not judged to be a prohibitive factor.

Under the conditions in which the study was made-providing a limited number of services in relation to current ongoing courses in the department of English within the period of one academic year-there is no evidence that the application of special library services and techniques to the college library provided more or better service to users than when they were not provided. Because there was some indication that the usefulness of the services may be broader and of more long-range value than their effect on a particular ongoing course, it is recommended that the same and other special library services be tested in the same and other fields over a longer period of time.

In addition to providing data bearing on the hypothesis, the study revealed certain general implications for further investigation concerning library service at the undergraduate level, directly or 
indirectly. These implications are merely hypotheses and have not been proved by the study.

Communications from professors indicated, to varying degrees, that the nature of the periodicals in the field of English language and literature is such that the undergraduate or the professor teaching undergraduate courses has evidently not been, generally speaking, those to whom the periodicals are directed. The potential of the use of periodicals to aid teaching and learning in this field cannot be known fully unless a number of articles are considered by professors to be appropriate for use in undergraduate courses.

Obviously, the provision of less expensive means of photoduplication would facilitate giving special library services. Two articles considered to be particularly valuable by the librarian giving the services would have cost professors $\$ 3.10$ and $\$ 1.90$ respectively, at the relatively low cost of ten cents per sheet.

Responses from professors indicated, to varying degrees, that they had little or no time to come to the library to follow up on notifications of appropriate available material. That professors' time is being saved by the services may not be apparent because they would not be scanning periodicals for appropriate material, etc., if the services were not offered. Delivery and pick-up service to and from faculty offices might be initiated where this service is not already offered.

Professors approved for ordering the majority of the filled-out order forms which had been sent to them. Although the department of English was covering current ordering (unaware that the forms would be sent from the library), these materials had been missed by the department of English, nor had the library attempted systematically to round out current ordering from this department. In two cases, where the bibliography in the textbook served in whole or in part as the course reading list, slightly less than half of the works listed in the textbook bibliography were held by the libraries. These instances of lack of control over the collection suggest that librarians might assume more definite responsibility, in practice as well as in theory, for the maintenance and development of the collection.

As would be expected, the use of allin-one textbooks, containing readings and bibliography as well as the usual textbook material, and the specifications by faculty members that students not use materials other than those provided in this one source or in the literary works used as texts, do not foster the use of special library services in connection with these courses.

Both phases of the study bore out the implication with respect to the lead time necessary for planned communication with the faculty in order to direct special library services most specifically to the needs of faculty and students. That professors were unaccustomed to receiving and using services not before offered may have been a deterrent to their fullest use.

The opportunity for communication with the faculty which the study afforded might be provided in the way most suitable to each institution as part of a regular, organized, and required routine. The study bore out the following of Knapp's findings:

Still the conscious analysis of the total curriculum in terms of the library resources, organization, and services appropriate for the several elements in it should result in something approaching a more rational library program than the relatively haphazard one in operation at present. ${ }^{2}$

In another connection, she states further:

But granted that the contribution of the

2 Patricia B. Knapp, College Teaching and the College Library (Chicago, ALA, 1959; ACRL Monograph No. 23), p. 97.

(Continued on page 152) 
officers agreed to state that the Board had seen no objection to the establishment of a new division, as recommended by COO. The new division was approved by the ALA Council on Thursday, January 27, under the title, "Information Science and Automation Division.")

A statement on preliminary planning for the administration of Title IIA of the Higher Education Act of 1965 was read by Miss Brown, including prospects for funds and preliminary and unofficial information for basic grants, applications from "combinations of institutions," supplemental grants, and special purpose grants. The information will be published in CRL in clarified form.

Robert Talmadge, chairman of the LAD Statistics Committee for College and University Libraries, reported the extensive reorganization of the U.S. Office of Educa- tion. Frank Schick has been transferred to the National Center for Educational Statistics. With this upheaval, a distribution of the questionnaires for statistics collection was delayed by four months. The future appears uncertain. USOE hopes to consolidate the questionnaires sent to academic institutions to include library data. However, ALA could get the data from USOE and publish it separately, if desired. The 1964/65 Statistics will appear as in the past, however.

A statistics conference is scheduled for June 1-3, 1966 (the dates were changed after the ACRL Board meeting) and will include approximately one hundred participants. The purpose is to determine what USOE wants from librarians and what the latter expects from USOE. The Handbook of Library Statistics should be published by April 1966.

The meeting was adjourned at 11:40 p.m.

\section{SPECIAL LIBRARY SERVICES}

\section{(Continued from page 13s)}

library is somewhat more limited than it has been proclaimed to be, a more important implication is that there is widespread lack of understanding or, at least, consensus among faculty and staff about what a library can and should contribute to the college-indeed, about what a library is. ${ }^{3}$

Unlike the training of high school teachers and administrators, the training of college faculty and administrators does not ordinarily include courses dealing with education on the college level. There is ordinarily no opportunity provided in the training of college faculty and administrators, therefore, to equip them to teach students to find and use multiple sources, or, indeed, to determine whether this is desirable. Nor is there opportunity provided to study ways in which teaching methods might fulfill these educational goals by using special library services and techniques as aids in these teaching methods.

The objectives of the study did not include the setting forth of a blueprint which college librarians might follow in

\footnotetext{
s Ibid., p. 93.
}

acting upon its conclusions and implications. One factor, however, appeared to the writer, as a subjective response, to be perhaps the major determinant of the future successful application of special library services and techniques to the college library in further experimentation: the attitude of college librarians toward the service program.

In order to determine exactly what educational goals are desirable and how they are best fulfilled, librarians, faculty, and administrators must be willing to divest themselves of preconceived ideas of what each "should" do and explore their roles on the basis of faculty and student need. The mere initiation of such discussions will be difficult and their outcome will undoubtedly indicate at least some change from present practice, bringing into play natural human resistance to change. It appeared to the writer, therefore, that the future service program in college libraries, whether or not special library services and techniques are ultimately applied, may well be a measure of the maturity of college librarians. 